\title{
eDNA als neues Werkzeug für das Gewässermonitoring - Potenzial und Rahmenbedingungen anhand ausgewählter Anwendungsbeispiele aus Österreich
}

\author{
Tamara Schenekar · Martin Schletterer · Steven Weiss
}

Online publiziert: 4. Februar 2020

(C) Der/die Autor(en) 2020

Zusammenfassung In den letzten Jahren wurden vermehrt DNA-basierte Methoden zur Unterstützung konventioneller Ansätze von Biodiversitätserhebungen vorgeschlagen. Hierbei wird der Verwendung von UmweltDNA (oder environmental DNA - eDNA) ein besonders großes Potenzial zur Verbesserung von Biomonitorings zugeschrieben. Anhand von eDNA kann man mittels Einzelartansätzen wie qPCRs gezielt Arten nachweisen, oder aber, mittels Metabarcoding die gesamte Artenzusammensetzung einer Zielgruppe beschreiben. In diesem Artikel geben wir einen kurzen Überblick über Potenzial und Rahmenbedingungen dieser Methoden und stellen drei kleine Pilotstudien von eDNA-Analysen in österreichischen Fließgewässern vor. Zwei Projekte testeten den Einsatz von eDNA-Metabarcoding-Analysen zur Erhebung der Fischfauna in Tiroler Gewässern, während in einer dritten Studie ein Test auf Anwesenheit der Europäischen Äsche in der Enns sowie im Johnsbach im Nationalpark Gesäuse evaluiert wurde. Des Weiteren werden die Vor- und Nachteile von eDNAbasierten Ansätzen im Vergleich mit konventionellen Methoden diskutiert.

Mag. Dr. T. Schenekar, Bakk.rer.nat. • Assoz. Univ.-Prof. Dr. S. Weiss ( $\varangle)$ Institut für Biologie,

Karl-Franzens-Universität Graz, Universitätsplatz 2/I, 8010 Graz, Österreich

steven.weiss@uni-graz.at

\section{Mag. Dr. M. Schletterer}

TIWAG - Tiroler Wasserkraft AG, Eduard-Wallnöfer-Platz 2, 6020 Innsbruck, Österreich

Institut für Hydrobiologie und Gewässermanagement, Universität für Bodenkultur Wien, Gregor-Mendel-Straße 33, 1180 Wien, Österreich
Schlüsselwörter Umwelt-DNA . Metabarcoding $\cdot \mathrm{qPCR} \cdot$ Monitoring

\section{eDNA as a novel tool for} freshwater monitoring-potential and framework conditions - with case studies from Austria

Abstract In the past few years, DNAbased methods have increasingly been promoted to support conventional biodiversity assessments. Hereby, the utilisation of environmental DNA (eDNA) has been suggested to possess a particularly high potential to improve biomonitoring. Using eDNA, one can assess the presence of individual target species via single-species approaches such as qPCRs, or describe compositions of target species communities via metabarcoding. We provide a brief review of the potential and challenges of these methods together with three small pilot case studies of eDNA analyses in Austrian rivers. Two such projects tested the application of eDNAmetabarcoding to assess fish communities in Tyrolian rivers, while a third example evaluated a protocol testing for the presence of European grayling in the rivers Enns and Johnsbach in the Gesäuse National Park. Furthermore, we discuss the benefits and challenges of eDNA-based methods in comparison to conventional approaches.

Keywords Environmental DNA . Metabarcoding $\cdot \mathrm{qPCR} \cdot$ Monitoring

\section{Gewässermonitoring in Europa - der Status quo}

Süßwassersysteme bieten ein breites Spektrum an Ökosystemdienstleistungen, wie beispielsweise die Bereitstellung von Trinkwasser, die Verwendung als Transportwege, für Hochwasserschutz und zur Energiegewinnung sowie auch als Lebensraum und für Erholungszwecke (Brauman et al. 2007).
Die intensive Nutzung von Süßwassersystemen führte hierbei jedoch $\mathrm{zu}$ Lebensraumveränderungen sowie $\mathrm{Be}$ lastungen dieser Ökosysteme (Dudgeon et al. 2006). Gleichzeitig beherbergen Süßwasserlebensräume und vor allem Fließgewässer jedoch eine ungleich hohe Biodiversität gemessen an ihrem flächenmäßigen Anteil an allen Ökosystem weltweit: Während Süßwassersysteme nur 0,8\% der weltweiten Erdoberfläche einnehmen (Gleick 1996), finden sich fast $6 \%$ aller beschriebenen Tierund Pflanzenarten in ihnen (Hawksworth und Kalin-Arroyo 1995; Gibert und Deharveng 2002). Diese extrem dichte Biodiversität, die starke Nutzung der Fließgewässer und die komplexen Einflussbereiche und -netzwerke, welche auf sie wirken, machen Flüsse global zu einer der am stärksten durch Biodiversitätsverlust gefährdeten Lebensräume (Dudgeon et al. 2006; WWF 2018; Díaz et al. 2019). Die Auswirkungen der Belastungen auf Süßwassersysteme und deren Lebensgemeinschaften können bereits weltweit beobachtet werden und ließen beispielsweise zwischen 1970 und 2012 die durchschnittliche Abundanz aller überwachten Tierund Pflanzenpopulationen in Süßgewässern um $81 \%$ sinken (WWF 2016). Um diesem Biodiversitätsverlust entgegenzuwirken und auch die nachhaltige Nutzung von Gewässersystemen zu gewährleisten, wurden weltweit legislative Werkzeuge ins Leben gerufen.

In diesem Kontext wurde auf europäischer Ebene im Jahr 2000 die Richtlinie 2000/60/EG erlassen, besser bekannt als Wasserrahmenrichtline (WRRL). Zentrale Elemente der Zielsetzungen der WRRL ist integratives Flussgebietsmanagement und eine laufende Überwachung des ökologischen Zustands der Oberflächengewässer (Muhar et al. 2011). Zur Erhebung des ökologischen Zustands eines Gewässers werden die Artzusammensetzung und Abundanz sogenannter biologischer Qualitätsele- 


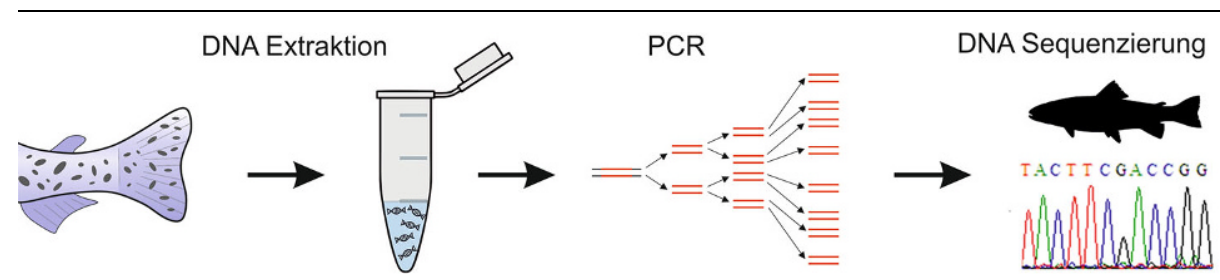

Abb. 1 Generierung eines DNA-Barcodes. Mittels DNA-Extraktion wird aus einer Gewebeprobe der Zielart DNA gewonnen. Aus dieser wird mittels Polymerasekettenreaktion (PCR) ein genetischer Marker amplifiziert. Durch DNA-Sequenzierung wird von diesem DNA-Fragment die DNA-Sequenz ausgelesen und so ein Barcode für diese Art erstellt

mente erhoben und mit der erwarteten Artenliste unter Referenzbedingungen verglichen. Je weiter hierbei der Ist-Zustand vom Referenzzustand abweicht, desto schlechter fällt die Bewertung des ökologischen Zustands aus ${ }^{1}$. Die Methoden zur Beprobung und Artbestimmung der biologischen Qualitätselemente wurden von den einzelnen Mitgliedstaaten entwickelt (z.B. BMLFUW 2015) und zwischenstaatlich zur Standardisierung interkalibriert (Birk und Böhmer 2007; Birk et al. 2013). Trotz Interkalibrierungen gibt es jedoch erhebliche Unterschiede bei Beprobungsaufwand, taxonomischer Auflösung und Metrikberechnungen zwischen den einzelnen Mitgliedstaaten (Birk et al. 2012). Was jedoch allen Methoden gemein ist, sind die morphologischen Methoden bei den taxonomischen Bestimmungsarbeiten zur Erhebung der biologischen Qualitätselemente. Diese erfordert naturgemäß das gezielte Aufsammeln von Individuen der Zielbioindikatorgruppe (mit Ausnahme der Makrophyten). Hierbei werden im Rahmen der Beprobung entweder Individuen der Zielbioindikatorgruppe komplett aus dem Gewässer entnommen und für die Analysen fixiert (z.B. Phyto- und Makrozoobenthos), oder zur Erhebung der Fischfauna, Elektrobefischungen herangezogen, wobei die Fische nach Artund Größenbestimmung sowie Wägung wieder in das Gewässer entlassen werden. Jedoch kann Elektrofischen unter bestimmten Bedingungen mit erheblichem materiellen und personellen Aufwand verbunden sein und stößt z. B. bei sehr großen Fließgewässern oder Seen an seine Grenzen. Während bei Fischen die Artbestimmung aufgrund

\footnotetext{
${ }^{1}$ Anm: Zusätzlich zu den Artenlisten sind bei den einzelnen biologischen Qualitätselementen weitere Faktoren für die Zustandsbewertung ausschlaggebend, so sind beispielsweise für das Qualitätselement „Fische“ die Altersstruktur und die Biomasse wichtige Parameter.
}

der überschaubaren Diversität verhältnismäßig schnell und im Feld erfolgen kann, kann dieser Arbeitsschritt bei komplexeren Bioindikatorgruppen wie Phytobenthos oder Makrozoobenthos je nach Erhebung durchaus mehrere Tage bis Wochen in Anspruch nehmen. Weiters wird hierfür fachlich spezialisiertes Personal benötigt, um die Bestimmungsarbeiten verlässlich durchführen zu können.

\section{Die Idee des DNA-basierten Monitorings}

In den letzten 10 bis 15 Jahren wurde für Biodiversitätserhebungen DNAbasiertes Monitoring als wertvolle Ergänzung zu den etablierten, konventionellen Erhebungsmethoden vorgeschlagen (Baird and Hajibabaei 2012; Hering et al. 2018). Hierbei soll die konventionelle taxonomische Bestimmungsarbeit durch genetische Ansätze unterstützt und ergänzt werden. Das Konzept, welches hierfür verwendet wird, ist das sogenannte DNA-Barcoding. DNA-Barcoding bezeichnet die taxonomische Zuordnung eines Tieroder Pflanzenexemplars basierend auf seiner DNA-Sequenz eines bestimmten genetischen Markers (Hebert et al. 2003). Hierfür wird die DNA aus einer Gewebeprobe des Exemplars extrahiert und der genetische Marker (im Falle von Tieren, das sogenannte Cytochrom-Oxidase-I-Gen, ein Teil des mitochondriellen Genoms) durch eine Polymerase-Kettenreaktion (oder „PCR“) vervielfältigt. Dieses amplifizierte DNAFragment wird danach sequenziert und die erhaltene DNA-Sequenz wird mit einer genetischen Referenzdatenbank abgeglichen (Abb. 1).

Die weltweite Initiative IBOL (International Barcode of Life) hat zum Ziel, solche genetische Referenzsequenzen dieser Marker für das gesamte multizelluläre Biodiversitätsspektrum unseres Planeten zu generieren, um so einerseits die genetische Diversität aller
Spezies weltweit zu charakterisieren, aber auch um weltweit genetische Artidentifikationen basierend auf diesen genetischen Barcodes zu ermöglichen (IBOL 2019). Dieser Ansatz stellt bereits eine vielversprechende Ergänzung zu morphologischen Bestimmungsarbeiten dar (beispielsweise bei morphologisch kryptischen Arten). Allerdings liegt ein noch weitaus größeres Potenzial für den Einsatz von genetischen Methoden im Biomonitoring in der Kombination des Barcoding-Ansatzes mit der Verwendung von eDNA (aus dem Englischen von „environmental DNA“), auch bekannt als Umwelt-DNA.

\section{Genetische Analysen mittels eDNA - Von artspezifischen Ansätzen bis hin zur Charakterisierung ganzer Artengesellschaften}

Der Begriff eDNA beschreibt jegliche Art von Genmaterial, welches von Organismen an Ihre Umwelt abgegeben wurde und wiederum aus einer Umweltprobe gewonnen werden kann, ohne den ursprünglichen DNA-Spender zuerst identifizieren oder isolieren zu müssen (Taberlet et al. 2012). Diese Umwelt-DNA kann dabei unterschiedlichsten Ursprungs sein. Im Falle von vielzelligen tierischen Organismen in Gewässern entstammt sie dabei meist abgestoßenen Gewebezellen oder Zellteilen, die beispielsweise durch das Abstreifen von Haut-, Schleim- oder Schuppenzellen oder durch Ausscheidungen wie Kot, Speichel, Blut oder Geschlechtsflüssigkeiten in das Wasser abgegeben wurden. Das Substrat, aus dem diese eDNA gewonnen werden kann, ist ebenso vielfältig wie der Ursprung der DNA und reicht von Wasserüber Bodenproben oder Sedimenten bis hin zu Luft oder dem Mageninhalt von Raubtieren oder blutsaugenden Insekten (Taberlet et al. 2012; Deiner et al. 2017; Ruppert et al. 2019). Im Falle von Fließgewässern wird eDNA 
eDNA Gewinnnung aus Wasserproben

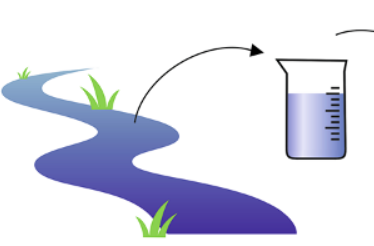

a

Probennahme

Artspezifischer Nachweis mittels qPCR
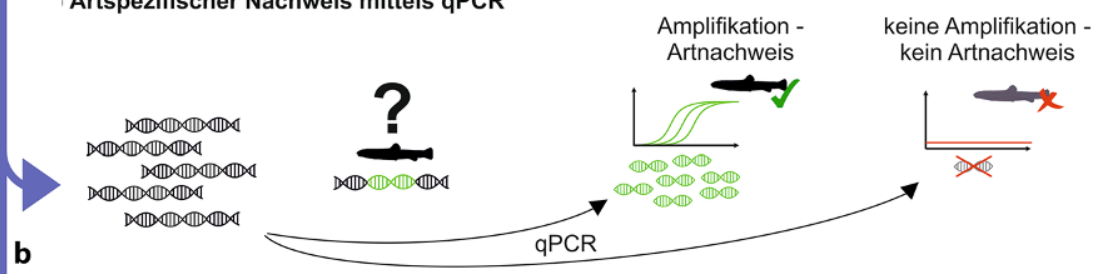

Nachweis aller Arten einer Zielgruppe mittels Metabarcoding

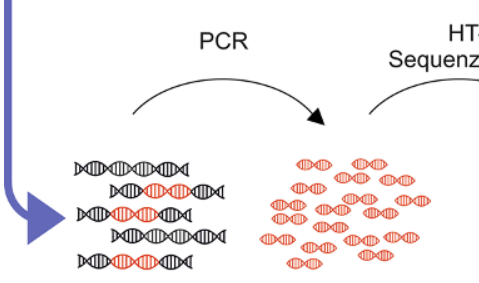

C

Abb. 2 Workflow von eDNA-Analysen an Gewässern mit zwei alternativen Ansätzen (Metabarcoding und artspezifische qPCR). a Ein definiertes Volumen an Wasser wird entnommen und filtriert, wobei die DNA auf dem Filter aufgefangen wird. Diese wird aus dem Filter durch DNA Extraktion gewonnen. $\mathbf{b}$ Ein genetischer Marker der Zielart soll aus der eDNA-Probe mittels qPCR amplifiziert werden. Ist DNA der Zielart vorhanden, lässt sich die Amplifikation in Echtzeit beobachten und die Art gilt als nachgewiesen. Ist keine DNA vorhanden, kommt es zu keiner Amplifikation und somit keinem Artnachweis. c Beim Metabarcoding wird ein genetischer Marker in der Zielgruppe aus der gesamten eDNA-Probe durch PCR vermehrt. Die PCR-Produkte werden danach mittels Hochdurchsatz (High Throughput-HT)-Sequenzierung ausgelesen. Die gewonnenen DNASequenzen (Barcodes) werden mit einer genetischen Referenzdatenbank der potenziell vorkommenden Arten verglichen. Wird der Barcode einer Art in den gewonnenen DNASequenzen gefunden, gilt diese als nachgewiesen

meist durch das Filtrieren von Wasserproben gewonnen (Abb. 2a). Das Konzept der Isolation von DNA aus Umweltproben ist per se nicht neu und wurde bereits in den 1990ern verwendet, um z.B. bakterielle oder andere mikrobielle Gemeinschaften in diesen Substraten zu charakterisieren (Coissac et al. 2012; Thomsen and Willerslev 2015; Deiner et al. 2017). Da hierbei jedoch die gesamten Organismen, welche analysiert werden, entnommen werden, werden solche Proben manchmal nur als eDNA-Proben im weiteren Sinne oder als "Community DNA“-Proben (zu Deutsch: Gesellschafts-DNA) definiert (Deiner et al. 2017). Die erste Studie, welche erstmalig eDNA gewonnen aus Wasserproben verwendete, um eine makrobiotische Art nachzuweisen, wurde 2008 durchgeführt: Ficetola et al. (2008) verwendeten DNA gewonnen aus Teichwasser, um den invasiven Nordamerikanischen Ochsenfrosch (Rana catesbeiana) in Frankreichs Gewässern nachzuweisen. Hierfür wurde die Gesamt-DNA in den entnommenen Wasserproben extrahiert und mittels eines artspezifischen Protokolls zur Amplifikation eines Barcodes selektiv für diese Art isoliert. Hierbei zeigte sich vor allem die hohe Sensitivität dieses
Ansatzes, wodurch sich auch bei sehr geringen Dichten des Ochsenfrosches ein positives Detektionssignal erhalten ließ, was vor allem für Erhebungen von invasiven, seltenen, bedrohten oder versteckt lebende Arten von entscheidendem Vorteil ist (Ficetola et al. 2008). Das Konzept solcher sogenannten "single-species“-Analysen (qPCRs; quantitative PCR, auch real-time PCR genannt), wurde danach für viele aquatische Organismen wie Fische (z. B. Carim et al. 2016; Roy et al. 2018), weitere Amphibien (Pilliod et al. 2013; Biggs et al. 2015) aber auch Wasserinsekten (Doi et al. 2017; Mauvisseau et al. 2019) und Krebstiere (Mächler et al. 2014; Robinson et al. 2018) angewendet. Im Gegensatz zum Metabarcoding (siehe unten) wird bei qPCR-Ansätzen die DNA in der eDNA-Probe nicht sequenziert. Auf die Anwesenheit der Ziel-DNA kann hierbei schon während der PCRReaktion, rein durch die Amplifikation (bzw. das Fehlen dieser) geschlossen werden (Abb. 2b). Dies ist bei der Untersuchung einzelner oder weniger Zielarten eine weitaus günstigere Alternative zum Metabarcoding und kann auch sensitiver bezüglich der Detektionswahrscheinlichkeiten sein (Harper et al. 2018; Bylemans et al. 2019). Während für die oben beschriebenen Ansätze die technischen Voraussetzungen bereits in den 1990ern vorhanden waren und der Schritt zur Anwendung dieser für Makroorganismen in z.B. Süßwassersystemen nur ein konzeptionelles Übertragen erforderte, war für die Idee, ganze Artengemeinschaften mittels eDNA zu charakterisieren, eine technologische Weiterentwicklung nötig. Diese erfolgte in den frühen 2000ern mit der Entstehung sogenannter „Next Generation Sequencing" (NGS) oder „High Throughput Sequencing“ (HTS)Methoden. NGS oder HTS beschreiben hierbei mehrere unterschiedliche Sequenziermethoden, welche von Firmen wie Thermo Fisher Scientific, Roche oder Illumina entwickelt wurden, um das rasche und parallele Sequenzieren von tausenden DNA-Molekülen in sehr kurzer Zeit zu ermöglichen. Dies ermöglichte einerseits die kosteneffiziente Entschlüsselung gesamter Genome einzelner Arten oder Individuen, ermöglichte aber auch den eDNAAnsätzen das Konzept des „Metabarcodings": Hierbei wird nun nicht gezielt der genetische Marker einer einzelnen Art aus der eDNA-Probe amplifiziert, sondern es werden mithilfe sogenann- 


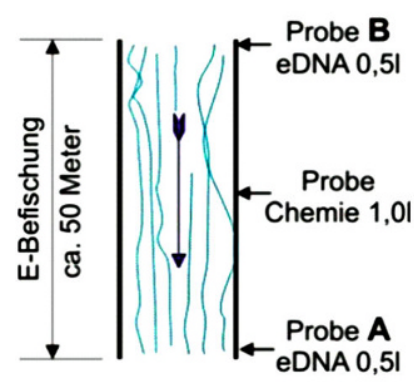

a

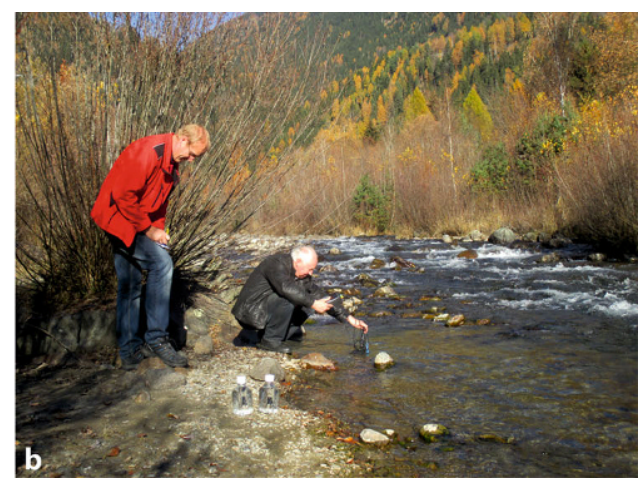

Abb. 3 a Schematische Skizze der Beprobung einer Befischungsstrecke im Rahmen des Pilotprojekts „E + eDNA“ in Osttirol b Messung physiko-chemischer Parameter
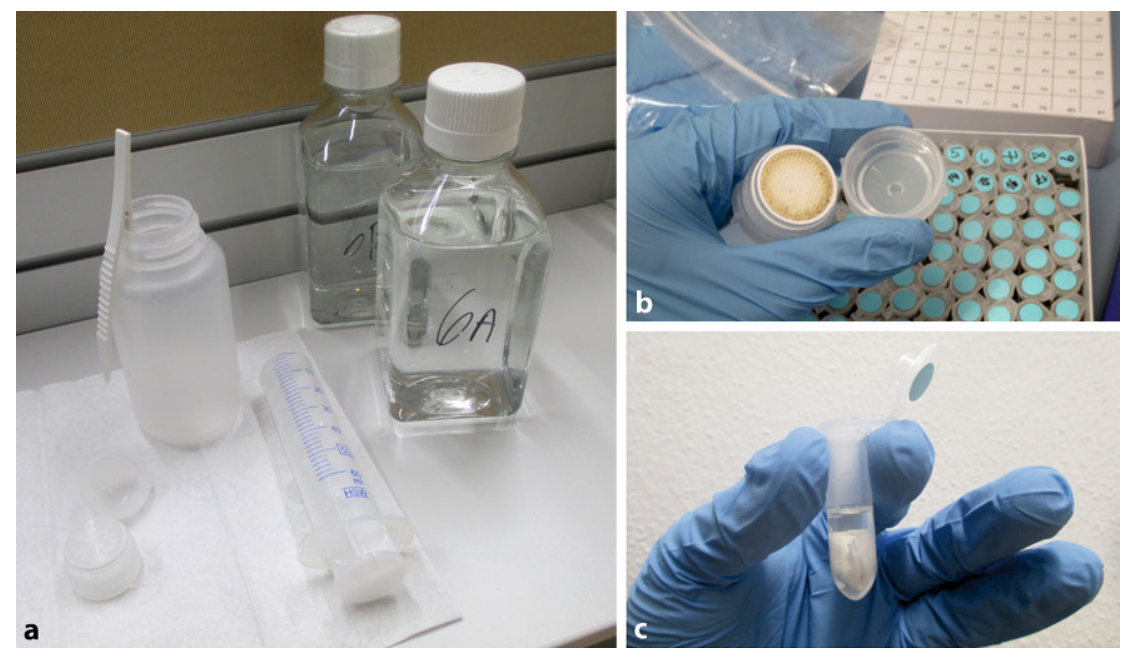

Abb. 4 Filtrieren der Probe im Labor: a Wasserproben mit Filtrier-Ausrüstung, b FilterHalter mit Filter nach der Filtration, c Filter in Eppendorf-Reaktionsgefäß mit LongmirePuffer

ter „universeller Primer“ die Barcodes aller Vertreter einer ausgewählten ZielArtengruppe (z. B. Kieselalgen, Wasserinsekten, Knochenfische) generiert, sofern sich von ihnen DNA in der eDNAProbe befindet. Durch Abgleich dieser parallel generierten Barcodes mit einer genetischen Referenzdatenbank lässt sich dann ein Gesamtbild der vorhandenen Arten dieser Zielgruppe in der Umgebung der Probe generieren (Abb. 2c).
4 Anwendungsmöglichkeiten von eDNA-Analysen anhand von drei Beispielen an Flusssystemen in Österreich

\subsection{Fallstudie 1: Pilotprojekt „E+eDNA“ - Osttirol (vgl. Weiss et al. 2018)}

\subsubsection{Fragestellung/Zielsetzung}

In diesem kleinen Pilotprojekt sollte das angewandte Beprobungsprokotoll erstmals ausgetestet und die Sensitivität dieses eDNA-Metabarcoding-Ansatzes mit konventionellen Methoden (Elektrobefischung) hinsichtlich der Detektionswahrscheinlichkeiten für Fischarten verglichen werden. Hierbei wurde das Einzugsgebiet der Isel flussauf von Lienz sowie der Debantbach auf das mögliche Vorkommen seltener Kleinfischarten mittels Elektrobefischungen
(Fischer und Gumpinger 2016) sowie eDNA-Beprobungen untersucht.

\subsubsection{Durchführung}

Im Oktober 2015 erfolgten an 25 Stellen qualitative Elektrobefischungen (vgl. BMLFUW 2015), wobei jeweils mindestens $50 \mathrm{~m}$ watend befischt wurden und selektiv auf Kleinfische gefischt wurde. Die eDNA-Probenahmen wurden im November 2015, etwa einen Monat nach der Elektrobefischung, bei günstigen Witterungsbedingungen (kein Niederschlag) durchgeführt. Zudem wurden hydrologische Bedingungen erhoben, Vor-Ort-Parameter (Temperatur, pH-Wert, Leitfähigkeit und Sauerstoffgehalt) gemessen und Wasserproben zur physiko-chemischen Analyse entnommen. An jeder Stelle wurden zwei Wasserproben (jeweils 0,5l) am unteren und oberen Ende der Befischungsstrecke entnommen (Abb. 3), welche für die eDNA-Analyse innerhalb von $24 \mathrm{~h}$ auf Glasfaser-Filter (GF-C bzw. GF-F) filtriert (Abb. 4) und in Puffer-Lösung (Longmire's solution; Longmire et al. 1997) bei Raumtemperatur gelagert wurden. Für jede Probenstelle wurde steriles Equipment (Handschuhe, 50ml-Spritze HSW 0535, SWINNEX Filterhalter $25 \mathrm{~mm}$, Plastik-Pinzette, Probengefäß) verwendet. In einem ersten Schritt wurde jeweils eine Kontrollprobe (destilliertes Wasser) filtriert und anschließend wurden die eigentlichen Teil-Proben filtriert. Anschließend wurde das Equipment in Bleiche $(2,5 \% \mathrm{Na}$ trium Hyperchlorid, 1:10 verdünnt) gereinigt (30 $\mathrm{min}$ ), in destilliertem Wasser gewaschen und wieder steril abgepackt. An drei Stellen (TWK01 - Wartschenbach, TWK02 - Debantbach, TWK06 Isel Zainer) wurden zu Vergleichszwecken Proben sowohl im Feld filtriert als auch unfiltrierte Proben ins Labor gebracht, wo diese innerhalb von $24 \mathrm{~h}$ filtriert wurden. Die weiteren Laborarbeiten erfolgten im Lodge Lab an der University of Notre Dame.

Die Extraktion der eDNA aus den Filtern erfolgte mittels des DNeasy Blood \& Tissues Kits (Qiagen, Hilden, Deutschland) mit Modifikationen (Deiner et al. 2015). Anschließend wurden drei Marker (12S rRNA, 16S rRNA, Cytochrom B) mittels universeller FischMetabarcoding-Primer (Burgener und Hübner 1998; Evans et al. 2016) amplifiziert. Die Metabarcoding-Library wurde unter Verwendung des Nextera XT DNA 96 Kits mit geringfügigen 


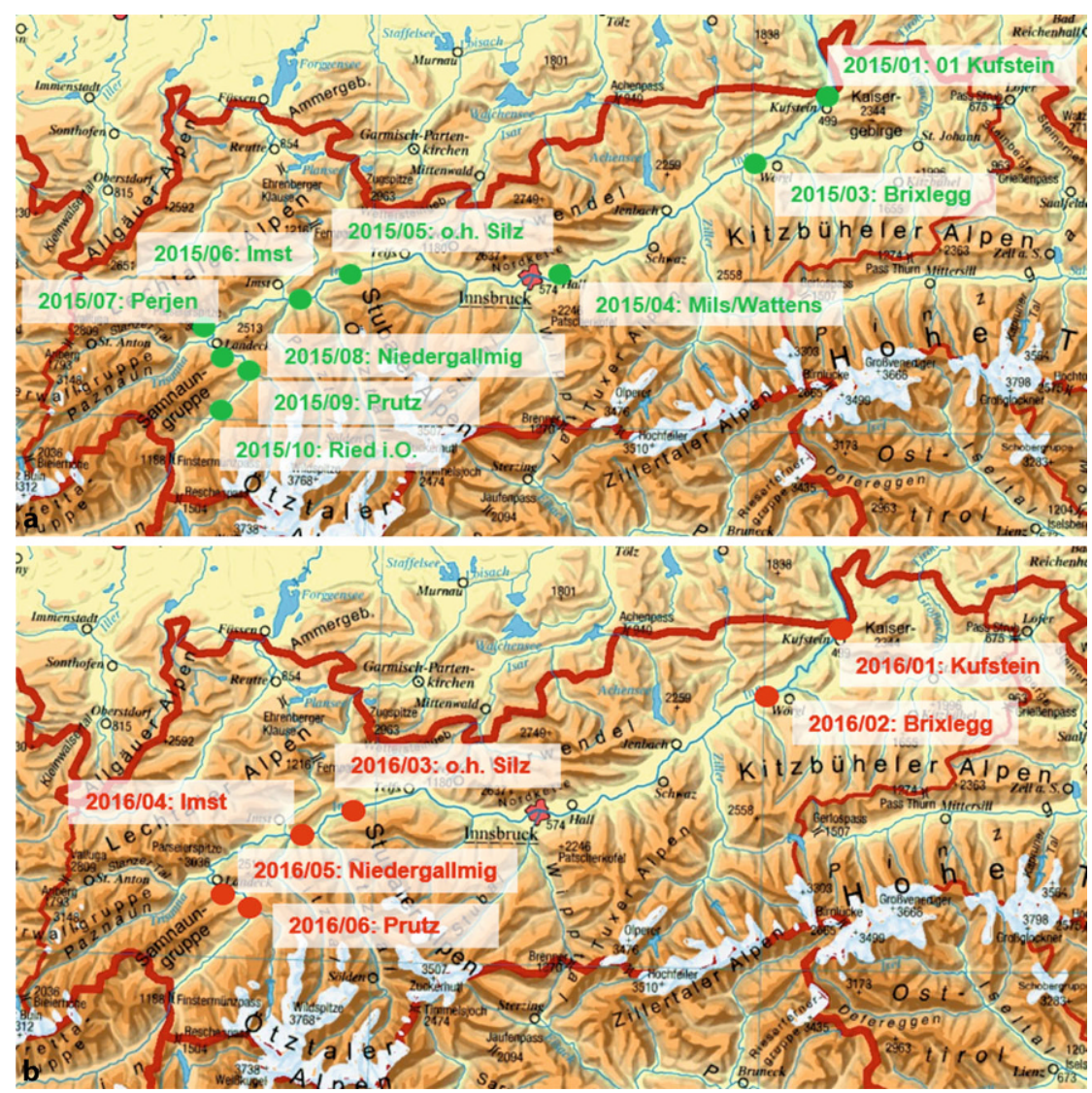

Abb. 5 eDNA-Beprobungsstellen am Tiroler Inn a 2015 und b 2016 (Kartengrundlage (C) Ed. Hölzl, www.hoelzel.at)

Modifikationen (Deiner et al. 2015) erstellt und mittels einem Illumina-MiSeq-Sequenzierer ausgelesen. Nach der Filterung der Rohdaten und Generierung der OTUs (Operational Taxonomic Units) erfolgte die Art-Zuordnung mithilfe einer selbstgenerierten Referenzdatenbank, welche durch Sequenzen von GenBank (https://www.ncbi.nlm. nih.gov/genbank) erstellt wurde.

\subsubsection{Ergebnisse}

Mithilfe des eDNA-Metabarcodings wurden insgesamt 14 Fischarten nachgewiesen, wobei die qualitativen Elektrobefischungen nur neun nachweisen konnten. Hierzu sei jedoch erwähnt, dass die Art der Elektro-Befischung nur qualitativ und in potenziell geeigneten Habitaten von Kleinfischarten erfolgte. Weiters wurde die Sensibilität der eDNA-Methodik durch verifizierbare Nachweise von Kleinfischarten aus Teichen im Einzugsgebiet (z. B. Sonnenbarsch - Lepomis gibbosus) untermauert. Die eDNA-basierten Ergebnisse lieferten eine (meist) vollständige
Erfassung der vorkommenden Fischarten in den Oberläufen und kleineren Gewässern, während in den größeren Vorflutern - insbesondere der Isel einige Arten nicht detektiert wurden. Dies unterstreicht die Notwendigkeit eines angepassten Probenvolumens bzw. einer angepassten Probenanzahl für größere Gewässer.

Weiters lieferte diese Pilotstudie zur Anwendung der eDNA-Methodik in Osttirol einen wesentlichen Beitrag zur methodischen Herangehensweise in alpinen Einzugsgebieten. So wurde gezeigt, dass sich bei Bearbeitung der Proben (Filtrierung der gekühlten Proben innerhalb von $24 \mathrm{~h}$ im Labor) keine Auffälligkeiten hinsichtlich der Detektierbarkeit von Fischarten (im Vergleich zu vor Ort filtrierten Proben) ergeben.

$$
\begin{aligned}
& 4.2 \text { Fallstudie 2: Pilotprojekt „E+ eDNA“ } \\
& \text { - Tiroler Inn }
\end{aligned}
$$

\subsubsection{Fragestellung/Zielsetzung}

In diesem Pilotprojekt wurde das Beprobungsprotokoll von Fallstudie 1 erst- mals an einem großen österreichischen Gewässer angewandt. Auch hier galt es, einen Methodenvergleich zwischen eDNA-Metabarcoding und konventionellen Methoden durchzuführen, wobei hier der Fokus des Performancevergleichs auf dem Tiroler Inn lag. Vor allem wurde hierbei der Einfluss des Probenvolumens der eDNA-Probennahme auf die Ergebnisse erhoben und diskutiert.

\subsubsection{Durchführung}

Im Herbst 2015 wurde im Zuge von Beweissicherungsmaßnahmen durch die ARGE Limnologie im Auftrag der TIWAG Elektrobefischungen an neun Abschnitten entlang des Tiroler Inns durchgeführt (Abb. 5; Schletterer et al. 2017; Hauer et al. in press). An der Stelle Fließ („Niedergallmig“) wurde 2015 eine Watbefischung (Kategorie A) und 2016 eine kombinierte Wat- und Bootsbefischung (Kategorie B) durchgeführt; alle anderen Stellen wurden mittels Bootsbefischung nach der Streifenbefischungsmethode (Kategorie C) befischt (vgl. BMLFUW 2015).

Die eDNA-Beprobungen wurden im Dezember 2015 und 2016 wieder jeweils am oberen sowie unteren Ende der Befischungsstrecken durchgeführt. Im Jahr 2015 wurde hierbei jeweils ein Gesamtvolumen von 11 mit zwei Teilproben $\mathrm{zu}$ je $500 \mathrm{ml}$ entnommen. Im Jahr 2016 wurden sechs der neun Probenstellen mittels eDNA erneut beprobt. Um eine höhere Sensitivität zu erreichen, wurde hierbei ein Gesamtvolumen von 31 mit jeweils sechs Teilproben (je zwei von beiden Uferseiten sowie zwei von der Flussmitte) zu je $500 \mathrm{ml}$ entnommen. Probenahme und Laborbearbeitung folgten der beschriebenen Methodik von Fallstudie 1. Hierbei erfolgte die Bearbeitung der Proben 2015 durch Kristy Deiner im Lodge Lab an der University of Notre Dame, die der Proben von 2016 durch Steven Weiss an der Universität Graz.

\subsubsection{Ergebnisse}

Durch die Elektrobefischungen wurden 2015 an den neun Probenstellen insgesamt 15 Fischarten nachgewiesen (Abb. 6 und 7). Mittels eDNA-Metabarcoding wurden im Jahr 2015 insgesamt 12 Arten detektiert (Abb. 7). Die Ergebnisse 2015 zeigen deutlich auf, dass ein Probenvolumen von 11 für ein Gewässer wie den Tiroler Inn zu gering 

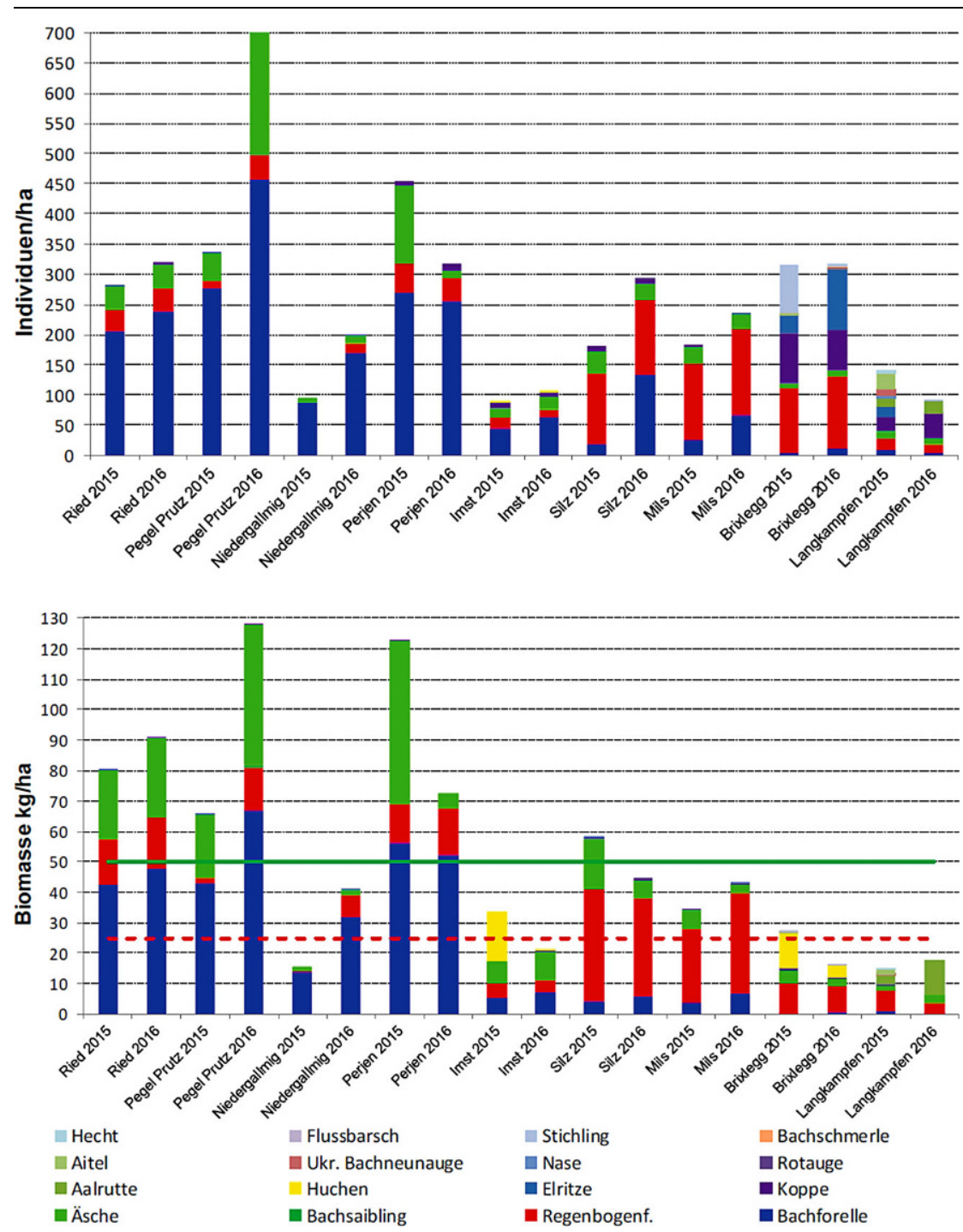

Abb. 6 Befischungsdaten 2015 und 2016 a Individuen je ha und b Biomasse (kg je ha). Aus: Hauer et al. (unpublished data)

ist, da zum Teil auch häufige Arten nicht detektiert werden konnten. Basierend darauf wurde entschieden, beim zweiten Beprobungsdurchgang (2016) die Beprobungsstrategie anzupassen (Probenahme entlang des Gewässerquerschnitts) und das Probenvolumen zu erhöhen.

Im Jahr 2016 wurden an den sechs Probenstellen insgesamt sieben Arten mittels eDNA detektiert. Unter den drei eingesetzten genetischen Markern (12S \& 16S rRNA sowie CytB), lieferten $16 \mathrm{~S}$ und CytB sehr ähnliche Ergebnisse: praktisch an allen Stellen wurden Äsche (Thymallus thymallus), Bachforelle (Salmo trutta), Bachsaibling (Salvelinus fontinalis), Koppe (Cottus gobio) und Regenbogenforelle (Oncorhynchus mykiss) nachgewiesen, lediglich fischungen und die eDNA-basierten Ergebnisse Unterschiede auf. Einerseits konnten einzelne, mittels Elektrobefischung nachgewiesene Arten durch eDNA nicht nachgewiesen werden, vermutlich aufgrund ihrer geringen Dichten (z. B. Gründling - Gobio gobio, oder Elritze). Weiters wurden Arten mittels eDNA detektiert, die in dem System nicht bekannt waren wie z.B. das Moderlieschen (Leucaspius delineatus) in Kufstein. Zu letzterem Beispiel stammt jedoch die nachgewiesene DNA vermutlich aus umliegenden Stillgewässern, welche in den Inn entwässern.

\subsection{Fallstudie 3: Nachweis von \\ Äschenwanderungen im \\ Nationalpark Gesäuse (vgl.}

Schenekar et al. 2019; Sturm 2019)

\subsubsection{Fragestellung/Zielsetzung}

Es sollte erhoben werden, ob der Mündungsbereich des Johnsbaches, ein $\mathrm{Zu}$ bringer der Enns im Nationalpark Gesäuse, für die Europäische Äsche (Thymallus thymallus) für z. B. Laichwanderungen passierbar ist. Da die Uferbereiche aufgrund brütender Flussuferläufer (Actitis hypoleucos) während des Untersuchungszeitraums nicht begehbar waren, konnten keine direkten Beobachtungen durchgeführt werden. Des Weiteren wurde von Elektrobefischungen aufgrund der Lage im Nationalpark abgesehen.

\subsubsection{Durchführung}

Im Nationalpark Gesäuse wurde im April bis Mai 2019 an insgesamt fünf Beprobungsstellen (drei Stellen an der Enns, zwei Stellen am Johnsbach; Abb. 8) eDNA-Beprobungen durchgeführt. Pro Stelle wurde ein Probenvolumen von 11 entnommen. Das entnommene Wasser wurde durch zwei bis 10 Glasfaserfilter (Whatman GF/F, Prorengröße 0,7 $\mu \mathrm{m}$ ) filtriert (je nachdem, wie viele Filter aufgrund von Verstopfungen benötigt wurden).

Diese Beprobungen wurden insgesamt vier mal, im Abstand von ca. je zwei Wochen wiederholt. Zusätzlich wurde noch eine weitere Beprobung im Oktober 2019 an den Stellen J1, J2 und E2 (Abb. 8) durchgeführt. Die DNA wurde aus den Filtern mittels eines modifizierten Phenol-Chloroform-Extraktions-Protokolls gewonnen (Sambrook et al. 1989; Renshaw et al. 2015) und zusätzlich mithilfe eines Kits (OneStep ${ }^{\mathrm{TM}}$ 


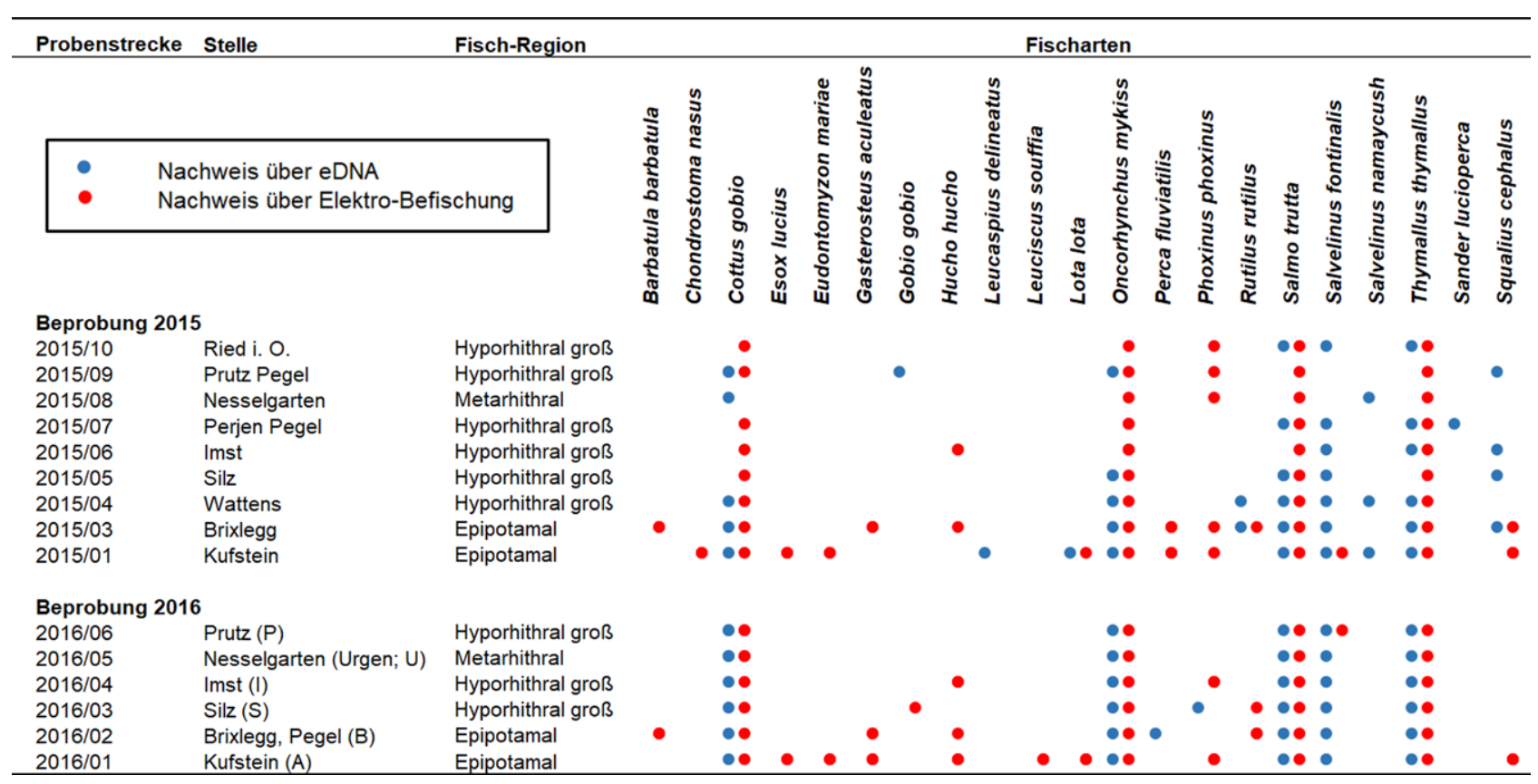

Abb. 7 Zusammenfassung der eDNA-Metabarcoding-Ergebnisse sowie der Elektro-Befischungen 2015 und 2016

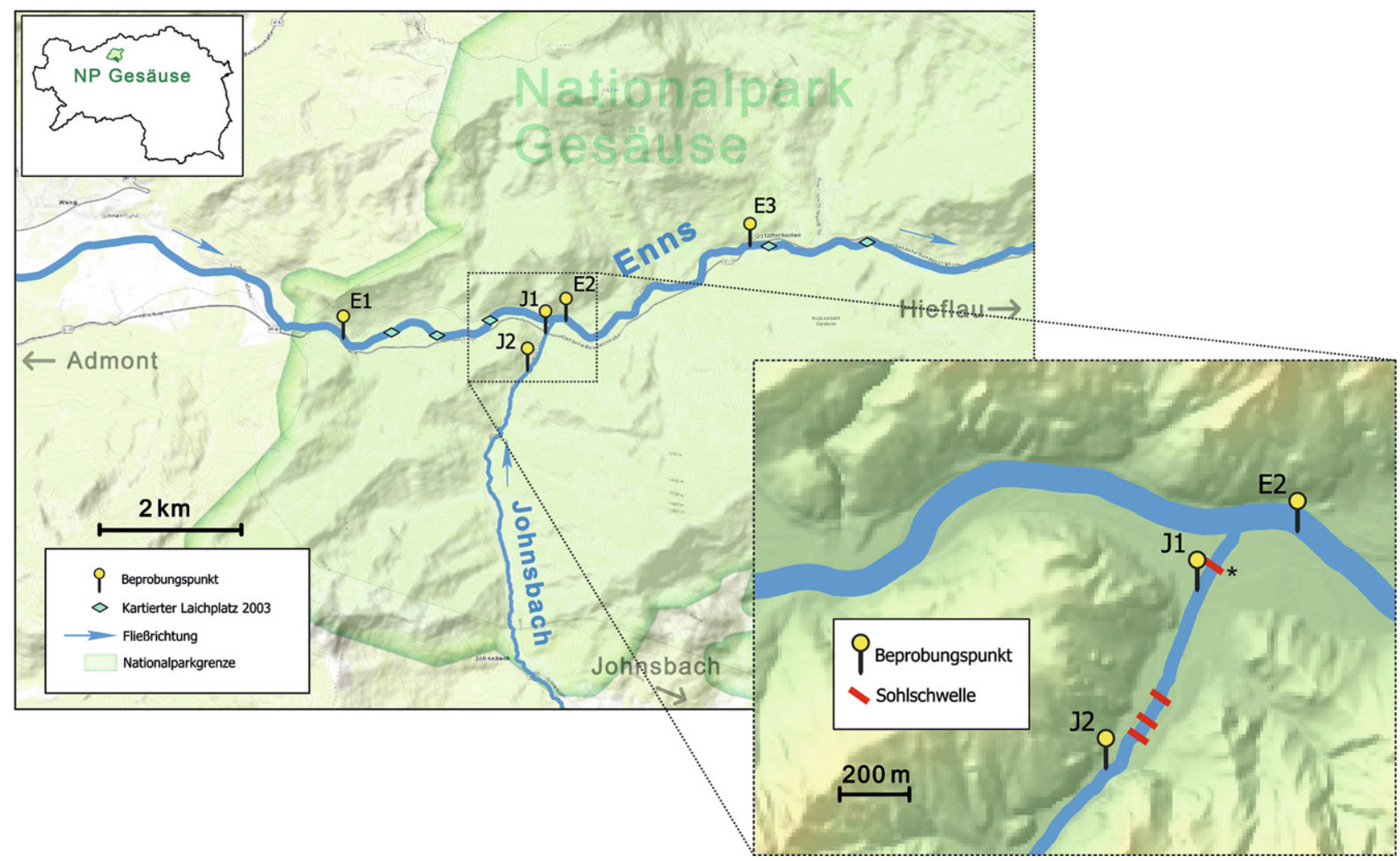

Abb. 8 Lage der Beprobungspunkte an der Enns und dem Johnsbach. E1: Enns-Gesäuseeingang; E2: Enns-Johnsbachsteg; E3: Enns-Gstatterboden; J1: Johnsbach Bachbrücke; J2: Johnsbach-Hellichter Stein. Grüne Diamanten zeigen vom NP Gesäuse 2003 kartierte Äschenlaichplätze an. * Natürliche Barriere, sehr dynamisch bei Hochwasserereignissen. Aus Schenekar et al. (2019) 


\begin{tabular}{|l|l|l|l|l|l|}
\hline & E1 & E2 & E3 & J1 & J2 \\
\hline 25.4.2019 & 8 & 7 & 8 & 1 & 3 \\
\hline 06.5.2019 & 4 & 8 & 7 & 1 & 0 \\
\hline 20.5 .2019 & 8 & 7 & 7 & 0 & 0 \\
\hline 27.5 .2019 & 8 & 8 & 8 & 2 & 2 \\
\hline 6.10 .2019 & N/A & 8 & N/A & 0 & 0 \\
\hline
\end{tabular}

Abb. 9 Heatmap der positiven-Amplifikationen an den einzelnen Beprobungsstellen and Enns und Johnsbach (Spalten), sowie Beprobungszeitpunkten (Zeilen). Rein negative Amplifikation sind weiß, höhere Amplifikationsraten durch Rotintensität dargestellt. Aus Schenekar et al. (2019)

PCR Inhibitor Removal Kit, Zymo Research) aufgereinigt. Für den Nachweis der Äsche wurde das qPCR-Protokoll von Carim et al. (2016) gewählt. Dieses Protokoll wurde ursprünglich für die Arktische Äsche (Thymallus arcticus) entwickelt. Daher wurde zunächst die Effizienz dieses Protokolls an Gewebeproben von Europäischen Äschen ausgetestet, welche sich als sehr zufriedenstellend bestätigte. An jeder der eDNA-Proben wurden danach jeweils acht PCR-Replikate durchgeführt, wobei für einen eindeutigen Positivnachweis mindestens zwei der acht Replikate Amplifikationen zeigen mussten.

\subsubsection{Ergebnisse}

Äschen-DNA konnte sowohl in der Enns als auch im Johnsbach nachgewiesen werden (Abb. 9). In der Enns wurde die Äsche hierbei zu allen Beprobungszeitpunkten und mit sehr hohen Amplifikationsraten (mindestens vier, meist alle acht PCR-Replikate) nachgewiesen. Im Johnsbach wurde Äschen-DNA an zwei Beprobungstagen (25.04. sowie 27.05.2019) eindeutig belegt. Die beiden Einzelamplifikationen an der Stelle J1 (25.04. und 06.05.2019) liegen unterhalb des gesetzten Grenzwerts von mindestens zwei Positivreplikaten und werden daher nicht als gewiss-positiv gezählt. Jedoch konnte aufgrund der Ergebnisse der Beprobungen vom 25.04. und 27.05. die Anwesenheit der Äsche im Johnsbach eindeutig belegt werden, welche womöglich durch Laichwanderungen eben dieser ausgelöst worden sein könnte. Die niedrigeren Amplifikationsraten im Vergleich zur Enns könnten durch die viel geringeren Dichten der Äsche im Johnsbach (vermutlich nur Einzelindividuen) erklärt werden. Um die Anwesenheit eventueller Jung- fische oder die dauerhafte Etablierung der Äsche im Johnsbach zu überprüfen, wurde die einmalige Beprobung im Oktober durchgeführt, welche jedoch keinen Hinweis auf die Äsche im Johnsbach zu dieser Zeit lieferte. So könnte es sein, dass der Johnsbach aufgrund seiner sehr hohen Geschiebedynamik kein geeignetes Laich- oder Jungfischhabitat darstellt.

\section{Diskussion}

\subsection{Vorteile von eDNA- und Metabarcoding-Ansätzen}

Zahlreiche Einzelstudien haben viele Vorteile des Metabarcodings gegenüber konventionellen Methoden bewiesen. Die wichtigsten sind hierbei (zusammengefasst von Goldberg et al. 2016; Hering et al. 2018; Harper et al. 2019; Ruppert et al. 2019): 1) Nicht-Invasivität: Konventionelle Methoden können die Zielarten oder -individuen stark beeinflussen und können damit im Konflikt mit den naturschutzrechtlichen Zielen stehen, zu deren Zwecken solche Erhebungen oft durchgeführt werden. eDNA-Beprobungen sind im Vergleich zu etablierten Methoden weniger invasiv. 2) Höhere Detektionswahrscheinlichkeiten: Seltene, bedrohte oder versteckt lebende Arten sind oft schwer mit konventionellen Methoden nachzuweisen. eDNA-Erhebungen können diese Arten mit einer höheren Wahrscheinlichkeit nachweisen. Besonders relevant ist dies auch bei invasiven Arten, wo es von höchster Priorität ist, diese bereits in einem sehr frühen Stadium der Besiedelung $\mathrm{zu}$ entdecken, um eine großräumige Ausbreitung zu vermeiden. 3) Geringerer Beprobungsaufwand: Konventionelle Beprobungsmethoden benötigen oft teure Gerätschaften, lange Beobachtungszeiträume oder geschultes Personal. eDNA-Beprobungen können nach einer kurzen Einschulung ohne kostspielige Ausrüstung durchgeführt werden. Dies erlaubt beispielsweise auch das großräumige Einsetzen von Citizen-Science-Projekten, wie sie bereits beispielsweise in Großbritannien (z. B. Biggs et al. 2015) und Österreich (z.B. Tirol; UIBK 2019) durchgeführt werden. 4) Bessere Zeitund Kosteneffizienz: Molekulargenetische Erhebungen sind aufgrund der andauernden Senkung der Sequenzierungskosten sowie der steten Steigerung von Computerrechenkapazitäten heute im Durchschnitt bereits kosten- günstiger und schneller durchzuführen als konventionelle Methoden. Dieser Trend wird sich voraussichtlich in $\mathrm{Zu}$ kunft noch weiter fortsetzen. 5) Weniger Expertisenengpässe: Die morphologische, taxonomische Identifizierung artenreicher Bioindikatorgruppen wie Algen oder Makroinvertebraten erfordert eine profunde Kenntnis dieser Gruppen. Die Ausbildung zu einem morphologischen Experten für diese Gruppe erfordert oft jahrelange Erfahrung, welche immer seltener zu finden ist. Das Feld der molekulargenetischen Analysen ist ein stetig wachsendes, weswegen zukünftig mit genügend verfügbarer Expertise zu rechnen ist. Daher wird in Zukunft jedenfalls eine Kombination der Methoden zielführend sein. Beispielsweise kann das konventionelle Monitoring, welches gemäß WRRL in der Regel in 6-Jahres-Zyklen stattfindet, durch eDNA ergänzt werden und durch den Einsatz der eDNA-Methodik die Monitoringfrequenz erhöht werden.

\subsection{Derzeitige Grenzen und Hindernisse von eDNA-Analysen}

Trotz des großen Potenzials und der oben genannten Erleichterungen, die eDNA-Ansätze für Biodiversitätserhebungen mit sich bringen können, gibt es jedoch einige Grenzen und Rahmenbedingungen, welche noch weitere Entwicklungsarbeiten erfordern, um solche Ansätze verlässlich als Werkzeug in diesem Feld einsetzen zu können. Die Hauptpunkte seien hier ebenfalls kurz zusammengefasst: 1) Das räumliche und zeitliche Ausmaß, auf das eDNA-basierende Ergebnisse bezogen werden können, kann von Habitat zu Habitat stark variieren. Beispielsweise wird DNA in der Wassersäule der meisten Süßwassersysteme meist innerhalb von Tagen abgebaut, während die DNA in Sedimenten von beispielsweise Seen über 100 Jahre und länger nachweisbar ist (Deiner et al. 2017; Ruppert et al. 2019). Der Flussabtransport von DNA in Flüssen kann ebenfalls stark variieren. So kann die Distanz zwischen den Spenderorganismen der DNA und den Beprobungsstellen mit positivem Detektionssignal zwischen wenigen hundert Metern und über 100 Kilometern variieren (Pont et al. 2018). Es wird daher noch immer mehr Grundlagenforschung für ein besseres Verständnis der eDNA-Dynamiken in den unterschiedlichen Habitaten benötigt (Thomsen and Willerslev 2015; Deiner et al. 2017; 
Hering et al. 2018). 2) Unterschiedliche Detektionswahrscheinlichkeiten einzelner Arten, verursacht durch verschiedene Schritte im Arbeitsablauf. Der Einfluss von Beprobungsdesign, DNA-Extraktion, Amplifikationen und bioinformatischer Auswertung auf die Detektionswahrscheinlichkeiten einzelner Arten müssen noch besser verstanden werden. Um möglichen Verzerrungen entgegenzuwirken, wurden bereits Richtlinien und „Goldstandards“ entwickelt, allerdings ist das Erstellen klar definierter Standards für einzelne Habitattypen erforderlich, um reproduzierbare und vergleichbare Ergebnisse zu liefern (Goldberg et al. 2016). 3) Aussagen über die Dichten und Abundanzen einzelner Arten sind noch immer stark umstritten. Einzelstudien unter (semi-)kontrollierten Bedingungen zeigen bereits vielversprechende Ergebnisse, eDNA-Abundanz mit der absoluten Artabundanz in Gewässern korrelieren $\mathrm{zu}$ können, jedoch benötigt es auch hier noch ein klareres Verständnis beispielsweise des Einflusses der Umweltfaktoren der jeweiligen Habitate auf solche Berechnungen (Carew et al. 2013; Bohmann et al. 2014; Goldberg et al. 2016; Hering et al. 2018). 4) Daten basierend allein auf eDNA können keine Informationen über wichtige demografische Parameter wie Populationsstruktur, Reproduktionsoder Migrationsraten wiedergeben. Des Weiteren kann die Methodik nicht zwischen lebendem und (relativ kürzlich) verstorbenem Ursprungsmaterial der analysierten DNA unterscheiden. Daher sind die erhaltenen Informationen über die Funktions- und Überlebensfähigkeit der ansässigen Population sehr begrenzt (Creer et al. 2016; Deiner et al. 2017). eDNA-Methoden sind daher zwar gut für Bioindikator-basierende Erhebungen geeignet, jedoch weniger nützlich, um z.B. Rückschlüsse auf die längerfristige ÖkosystemIntegrität zu ziehen. 5) eDNA-Analysen arbeiten mit sehr geringen Mengen an DNA. Daher ist das Risiko von Kontaminationen besonders hoch. Standards für die Vermeidung und zur Kontrolle von Kontaminationen, die zu Falsch-Positiven führen können, müssen entwickelt werden (Thomsen and Willerslev 2015; Goldberg et al. 2016). 6) Die benötigten genetischen Referenzdatenbanken sind derzeit bei Weitem noch nicht komplett. Auch wenn diesbezüglich zurzeit in Europa die größten Fortschritte erzielt wurden, was nationalen und internationalen Initiativen wie IBOL, ABOL (Austrian Barcode of Life) oder GBOL (German Barcode of Life) zu verdanken ist, gibt es sehr starke Variationen in der Abdeckung einzelner Taxongruppen. Es ist noch eine erhebliche Datenergänzung für artenreiche Gruppen wie Kieselalgen oder Makroinvertebraten notwendig (Kvist 2013; Thomsen and Willerslev 2015; Weigand et al. 2019).

\section{Ausblick}

Der Einsatz von eDNA-Methoden (sowohl Metabarcoding als auch Einzelartansätze) bietet viele Möglichkeiten, derzeitige Gewässermonitoring-Methoden zu unterstützen und zu ergänzen. Er kann eindeutige Ergebnisse liefern, wo konventionelle Methoden an ihre Grenzen stoßen und weist einen hohen Kosten-Nutzen-Faktor auf. Vor allem in Bezug auf invasive, seltene, bedrohte oder versteckt lebende Arten können die hochsensitiven eDNAAnsätze wertvolle Beiträge für Monitoringarbeiten liefern. Allerdings bedarf es bei der Interpretation von eDNAAnalysen eines klaren Verständnisses der Rahmenbedingungen, sowohl habitatbezogen als auch methodeninherent. Die Grundlagenforschung mit und an eDNA-Ansätzen schreitet rasant voran und lässt weitere spannende Entwicklungen dieser Methoden sowie darauf basierender Ergebnisse für das Gewässermanagement erwarten.

Funding Open access funding provided by University of Graz.

Open Access Dieser Artikel wird unter der Creative Commons Namensnennung 4.0 International Lizenz veröffentlicht, welche die Nutzung, Vervielfältigung, Bearbeitung, Verbreitung und Wiedergabe in jeglichem Medium und Format erlaubt, sofern Sie den/die ursprünglichen Autor(en) und die Quelle ordnungsgemäß nennen, einen Link zur Creative Commons Lizenz beifügen und angeben, ob Änderungen vorgenommen wurden.

Die in diesem Artikel enthaltenen Bilder und sonstiges Drittmaterial unterliegen ebenfalls der genannten Creative Commons Lizenz, sofern sich aus der Abbildungslegende nichts anderes ergibt. Sofern das betreffende Material nicht unter der genannten Creative Commons Lizenz steht und die betreffende Handlung nicht nach gesetzlichen Vorschriften erlaubt ist, ist für die oben aufgeführten Weiterverwendungen des Materials die Einwilligung des jeweiligen Rechteinhabers einzuholen.

Weitere Details zur Lizenz entnehmen Sie bitte der Lizenzinformation auf http://creativecommons.org/licenses/ by/4.0/deed.de.

\section{Literatur}

Baird, D.J., and M. Hajibabaei (2012): Biomonitoring 2.0: A new paradigm in ecosystem assessment made possible by next-generation DNA sequencing. Mol Ecol 21:2039-2044

Biggs, J., N. Ewald, A. Valentini, et al (2015): Using eDNA to develop a national citizen science-based monitoring programme for the great crested newt (Triturus cristatus). Biol Conserv 183:19-28. doi: 10.1016/j.biocon.2014.11.029 Birk, S., Böhmer, J. (2007): Die Interkalibrierung nach EG-Wasserrahmenrichtlinie - Grundlagen und Verfahren. Wasserwirtschaft 9: 10-14

Birk, S., W. Bonne, A. Borja, et al (2012): Three hundred ways to assess Europe's surface waters: An almost complete overview of biological methods to implement the Water Framework Directive. Ecol Indic 18:31-41. doi: 10.1016/j.ecolind. 2011.10.009
Birk, S., E. Bellak, Böhmer, J., et al (2013): Die Interkalibrierung nach EG-Wasserrahmenrichtlinie - Neue Ergebnisse und Resümee. Wasserwirtschaft 1/2:52-55

BMLFUW (2015): Leitfaden für die Erhebung der biologischen Qualitätselemente. Online: https:// www.bmnt.gv.at/wasser/wasser-oesterreich/ plan_gewaesser_ngp/nationaler_gewaesser bewirtschaftungsplan-ngp/bio_lf.html. Zugegriffen: 22.1.2020

Bohmann, K., A. Evans, M.T.P. Gilbert, et al (2014): Environmental DNA for wildlife biology and biodiversity monitoring. Trends Ecol Evol 29:358-367. doi: 10.1016/j.tree.2014.04.003

Brauman, K.A., G.C. Daily, T.K. Duarte, and H.A. Mooney (2007): The Nature and Value of Ecosystem Services: An Overview Highlighting Hydrologic Services. Annu Rev Environ Re- sour 32:67-98. doi: 10.1146/annurev.energy.32. 031306.102758

Burgener, M., Hübner, P. (1998): Mitochondrial DNA enrichment for species identification and evolutionary analysis. Z Lebensm Unters Forsch 207:261-263. doi: 10.1007/s002170050329

Bylemans, J., Gleeson, D.M., Duncan, R.P., et al (2019): A performance evaluation of targeted eDNA and eDNA metabarcoding analyses for freshwater fishes. Environ DNA 402-414. doi: 10.1002/edn3.41

Carew, M.E., V.J. Pettigrove, L. Metzeling, and A.A. Hoffmann (2013): Environmental monitoring using next generation sequencing: rapid identification of macroinvertebrate bioindicator species. Front Zool 10:45. doi: 10.1186/17429994-10-45 
Carim, K.J., J.C.S. Dysthe, M.K. Young, et al (2016): An environmental DNA assay for detecting Arctic grayling in the upper Missouri River basin, North America. Conserv Genet Resour 8:197-199. doi: 10.1007/s12686-016-0531-1 Coissac, E., T. Riaz, and N. Puillandre 2012. „Bioinformatic challenges for DNA metabarcoding of plants and animals." Mol Ecol 21:1834-1847. doi: 10.1111/j.1365-294X.2012.05550.x

Creer S., K. Deiner, S. Frey, et al (2016): The ecologist's field guide to sequence-based identification of biodiversity. Methods Ecol Evol 7:1008-1018. doi: 10.1111/2041-210X.12574 Deiner, K., H.M. Bik, E. Mächler, et al (2017): Environmental DNA metabarcoding: Transforming how we survey animal and plant communities. Mol Ecol 26:5872-5895. doi: 10.1111/mec. 14350

Deiner, K., Walser, J.-C., Maechler, E., Altermatt, F (2015): Choice of capture and extraction methods affect detection of freshwater biodiversity from environmental DNA. Biol Conserv 183:53-63. doi: 10.1016/j.biocon.2014.11.018

Doi, H., I. Katano, Y. Sakata, et al (2017): Detection of an endangered aquatic heteropteran using environmental DNA in a wetland ecosystem. R Soc OPEN Sci 4:. doi: 10.1098/rsos.170568 Dudgeon, D., A.H. Arthington, M.O. Gessner, et al (2006): Freshwater biodiversity: Importance, threats, status and conservation challen ges. Biol Rev Camb Philos Soc 81:163-182. doi 10.1017/S1464793105006950

Díaz, S., Settele, J., Brondízio, E. (2019): Summary for policymakers of the global assessment report on biodiversity and ecosystem services. Online: https://ipbes.net/global-assessmentreport-biodiversity-ecosystem-services. Zugegriffen: 22.1.2020

Evans, N.T., Olds, B.P., Renshaw, M.A, et at (2016): Quantification of mesocosm fish and amphibian species diversity via environmental DNA metabarcoding. Mol Ecol Resour 16:29-41. doi: 10.1111/1755-0998.12433

Ficetola, G.F., C. Miaud, F. Pompanon, and P.Taberlet (2008:) Species detection using environmental DNA from water samples. Biol Let 4:423-425. doi: 10.1098/rsbl.2008.0118

Fischer, A., and C. Gumpinger (2016): Erfassung von Beständen ausgewählter Kleinfischarten mit Schwerpunkt auf der Koppe (Cottus gobio) in den Einzugsgebieten der Isel und des Debantbachs. 57 pp, Studie im Auftrag der Tiroler Umweltanwaltschaft, des Nationalparks Hohe Tauern und des Tiroler Fischereiverbandes

Gibert, J., and L. Deharveng (2002): Subterranean Ecosystems: A Truncated Functional Biodiversity. Bioscience 52:473-481. doi: 10.1641/ 0006-3568(2002)052[0473:SEATFB]2.0.CO-2

Gleick, P.H. (1996): Water resources. In: Schneider SH (ed) Encyclopedia of Climate and Weather. Oxford Unviersity Press, New York, pp 817 823

Goldberg, C.S., C.R. Turner, K. Deiner, et al (2016): Critical considerations for the application of environmental DNA methods to detect aquatic species. Methods Ecol Evol 7:1299-1307. doi: 10.1111/2041-210X.12595

Harper, L.R., Lawson Handley, L., Hahn, C., et al (2018): Needle in a haystack? A comparison of eDNA metabarcoding and targeted qPCR for detection of the great crested new (Triturus cristatus). Ecol Evol 8:6330-6341. doi $10.1002 /$ ece 3.4013
Harper, L.R., A.S. Buxton, H.C. Rees, et al (2019): Prospects and challenges of environmental DNA (eDNA) monitoring in freshwater ponds. Hydrobiologia 826:25-41. doi: 10.1007/ s10750-018-3750-5

Hauer, C., M. Haimann., P. Holzapfel, et al. (unpublished data): Controlled reservoir drawdown-challenges for sediment management and integrative monitoring: an Austrian case study_Part A: Reach scale.

Hawksworth, D.J., Kalin-Arroyo, M.T. (1995): Magnitude and distribution of biodiversity. In: Heywood VH (ed) Global biodiversity Assessment. Cambridge University Press, Cambridge, pp 107-191

Hebert, P.D.N., Cywinska, A., Ball, S.L., DeWaard, J.R. (2003): Biological identifications through DNA barcodes. Proc R Soc B Biol Sci 270:313-321. doi: 10.1098/rspb.2002.2218

Hering, D, Borja, A., Jones, J.I, et al (2018): Implementation options for DNA-based identification into ecological status assessment under the European Water Framework Directive. Water Res 138:192-205. doi: 10.1016/j.watres.2018.03.003 IBOL (2019): Our Vision. https://ibol.org/about/ our-vision/. Accessed 1 Nov 2019

Kvist, S. (2013): Barcoding in the dark?: A critical view of the sufficiency of zoological DNA barcoding databases and a plea for broader integration of taxonomic knowledge. Mol Phylogene Evol 69:39-45. https://doi.org/10.1016/j.ympev. 2013.05.012

Longmire, J.L., Maltbie, M., Baker, R.J. (1997): Use of "Lysis Buffer“ in DNA isolation and it implication for museum collections, Museum of Texas Tech University, Lubbock

Mächler, E., K. Deiner, P. Steinmann, and F. Altermatt (2014): Utility of environmental DNA for monitoring rare and indicator macroinvertebrate species. Freshw Sci 33:1174-1183. doi 10.1086/678128.

Mauvisseau, Q., J. Davy-Bowker, M. Bulling, et al (2019): Combining ddPCR and environmental DNA to improve detection capabilities of a critically endangered freshwater invertebrate. $S c i$ Rep 9:. doi: 10.1038/s41598-019-50571-9

Muhar, S., Pohl, G., Stelzhammer, M. et a (2011): Integratives Flussgebietsmanagement: Abstimmung wasserwirtschaftlicher, gewässerökologischer und naturschutzfachlicher Anforderungen auf Basis verschiedener EU-Richtlinien (Beispiel Steirische Enns). Österr Wasserund Abfallw 63:167-173. doi:10.1007/s00506011-0336-0

Pilliod, D.S., C.S. Goldberg, R.S. Arkle, L.P. Waits (2013): Estimating occupancy and abundance of stream amphibians using environmental DNA from filtered water samples. Can J Fish Aquat Sci 70:1123-1130. doi: 10.1139/cjfas-2013-0047

Pont, D., M. Rocle, A. Valentini, et al (2018): Environmental DNA reveals quantitative patterns of fish biodiversity in large rivers despite its downstream transportation. Sci Rep 8:1-13. doi: 10.1038/s41598-018-28424-8

Renshaw, M.A., Olds, B.P., Jerde, C.L., et al (2015): The room temperature preservation of filtered environmental DNA samples and assimilation into a phenol-chloroform-isoamyl alcohol DNA extraction. Mol Ecol Resour 15:168-176. doi: 10.1111/1755-0998.12281

Robinson, C.V., T.M. Uren Webster, J. Cable, et al (2018): Simultaneous detection of invasive signal crayfish, endangered white-clawed crayfish and the crayfish plague pathogen using environmental DNA. Biol Conserv 222:241-252. doi: 10.1016/j.biocon.2018.04.009 Roy, M., V. Belliveau, N.E. Mandrak, N. Gagné (2018): Development of environmental DNA (eDNA) methods for detecting high-risk freshwater fishes in live trade in Canada. Biol Invasions 20:299-314. doi: 10.1007/s10530-0171532-z

Ruppert, K.M., R.J. Kline, M.S. Rahman (2019): Past, present, and future perspectives of environmental DNA (eDNA) metabarcoding: A systematic review in methods, monitoring, and applications of global eDNA. Glob Ecol Conserv 17:1-29. doi: 10.1016/j.gecco.2019.e00547

Sambrook, J., Fritsch, E., Maniatis, T. (1989): Molecular cloning. A laboratory manual. Cold Spring Harbor Laboratory Press, NewYork Schenekar, T., Sturm, S., Weiss, S. (2019): Auf den Spuren der Äsche im Gesäuse: Nachweis und Kartierung von Thymallus thymallus in der Enns und dem Johnsbach mittels eDNA. Österreichs Fischerei Heft 11/12:297-309

Schletterer, M., B. Hofer, R. Obendorfer R. et al. (2017): Integrative monitoring approaches for the sediment management in Alpine reservoirs: case study Gepatsch (HPP Kaunertal, Tyrol). in: Wieprecht, S., Haun, S., Weber, K., Noack, M., Terheiden, K. (Eds.): River Sedimentation, pp. 1161-1169 Proceedings of the 13th International Symposium on River Sedimentation (Stuttgart, Germany, 19-22 September, 2016), Taylor \& Francis, ISBN: 978-1-138-02945-3.

Sturm, S. (2019): Nachweis und Kartierung von Thymallus thymallus im Nationalpark Gesäuse. Diplomarbeit, Institut für Biologie, Karl-Franzens University Graz.

Taberlet, P., E. Coissac, M. Hajibabaei, and L.H. Rieseberg (2012): Environmental DNA. Mol Ecol 21:1789-1793. doi: 10.1111/j.1365294X.2012.05542.X

Thomsen, P.F., and E. Willerslev (2015): Environmental DNA-An emerging tool in conservation for monitoring past and present biodiversity. Biol Conserv 183:4-18. doi: 10.1016/j.biocon. 2014.11.019

UIBK (2019): Wissenschaft für alle: Der Frosch im Wassertropfen. Medieninformation 5.4.2019, online: https://www uibk ac at/public-relations/ presse/archiv/2019/1125/.Zugegriffen: 22.1.2020 Weigand, H., A.J. Beermann, F. Čiampor, et al (2019): DNA barcode reference libraries for the monitoring of aquatic biota in Europe: Gapanalysis and recommendations for future work. bioRxiv 576553. doi: 10.1101/576553

Weiss, S., K. Deiner, J. A. Tuhtan, C. Gumpinger, and M. Schletterer (2018): Genetische Analysen von Fischbeständen: Populationsgenetik und eDNA. Wasserwirtschaft 2-3:22-29

WWF (2016): Living Planet Report 2016 Risk and resilience in a new era. Gland, Swirtzerland

WWF (2018): Living Planet Report 2018: Aiming higher. Gland, Switzerland

Hinweis des Verlags Der Verlag bleibt in Hinblick auf geografische Zuordnungen und Gebietsbezeichnungen in veröffentlichten Karten und Institutsadressen neutral. 